\title{
CALIBRATION OF TOTAL NITROGEN CONTENT IN SEAWEEDS (Ulva sp.) BY NIRS
}

\author{
L. Bonnal ${ }^{1 *}$, P. Cacot ${ }^{2}$, G. Boissier ${ }^{2}$, M. Hébert ${ }^{2}$, T. Geoffroy ${ }^{3}$, D. Bastianelli ${ }^{1}$ \\ ${ }^{1}$ CIRAD,UMR SELMET Animal feed laboratory, 34398 Montpellier Cedex 5, France. \\ ${ }^{2}$ CIRAD, UMR 116 ISEM (Institute of Evolution Sciences in Montpellier), 34250 Palavas-les-Flots, France. \\ ${ }^{3}$ IFREMER, Palavas aquaculture research station, 34250 Palavas-les-Flots, France.
}

Corresponding author: laurent.bonna@@cirad.fr

Invasive sea lettuce (Ulva sp.) could be valorized in fish feeding insofar as protein content is increased. Direct NIRS measurement on fresh seaweed was tested as tool for monitoring protein enrichment of algae in different cultivation conditions. Spectra were collected on fresh spin-dried samples of algae with an ASD Labspec Pro spectrometer. The results of NIRS calibrations for dry matter (DM), total nitrogen (N) and total minerals (ash) on fresh samples led robust calibrations with SEP and $R^{2}$ values of $1.08 \%$ and 0.93 for DM, 0.49\%DM and 0.95 for $\mathrm{N}, 2.45 \% \mathrm{DM}$ and 0.74 for ash. In order to compare calibration precision, calibrations were also developed on dried samples spectra collected on Foss NIRSYSTEM 6500 spectrometer. This study showed the interest of direct NIRS measurement as tool to daily monitoring the enrichment of algae (especially the protein content based on the $\mathrm{N}$ content) and its potential for decisions on harvest when $\mathrm{N}$ concentration reach a plateau.

KEYWORDS: Nitrogen, seaweeds, Ulva, culture, near infrared spectroscopy

\section{INTRODUCTION}

Seaweeds as sea lettuce (Ulva sp.) are common on French seashore. In some conditions they can even become invasive and cause environmental problems. Their valorization in animal feeding would be valuable, but it is limited by their low protein content (around 10\%DM). In the framework of studies on protein enrichment of algae, there was a need for tools for monitoring the kinetics of protein accretion when cultivated in fertilized waters. Non-destructive direct measurement by NIRS on fresh samples was tested to evaluate the potential of this tool. In addition, NIRS measurements were also performed in the laboratory on dried samples to evaluate NIRS for more precise measurements.

\section{MATERIALS AND METHODS}

Algae were collected in the coastal ponds around Palavas (southern France) and cultivated in three different culture conditions in sea water tanks. The first culture condition consisted in three $3 \mathrm{~m}^{2}$ tanks with stagnant water and Nitrogen (as $\mathrm{NH}_{4} \mathrm{Cl}$ ) and phosphorus (as $\left.\mathrm{KH}_{2} \mathrm{PO} 4\right)$ inputs. The second culture condition consisted in two 12 $\mathrm{m}^{2}$ tanks with turbulent water and the same fertilizers plus $\mathrm{CO}_{2}$ gas and iron gluconate. The third culture condition consisted in three $3 \mathrm{~m}^{2}$ tanks with stagnant water and no fertilization (control treatment). The water depth was $0.5 \mathrm{~m}$ in all the tanks. They were sampled at least once a week over three months, leading to a total of 213 samples. Samples were rinsed with freshwater and excess water was removed in a spinner (1200 RPM for 5 minutes) of a washing machine.

NIR spectra on fresh spin-dried samples were collected in reflectance mode with a Labspec Pro spectrometer (ASD, Boulder, CO, USA), with a High Intensity Contact Probe (spot diameter $10 \mathrm{~mm}$ ). Each sample was scanned 20 times and spectra were averaged. Samples were then oven-dried $\left(55^{\circ} \mathrm{C}\right)$ and ground $(1 \mathrm{~mm}$ sieve). Dry matter content (DM55 at $55^{\circ} \mathrm{C}$ and DM at $\left.103^{\circ} \mathrm{C}\right)$, total nitrogen (N, Kjeldahl method, NF EN ISO 5983-2) and total minerals (ash, $550^{\circ} \mathrm{C}$ ) were determined in the laboratory. Spectra on dried and ground samples were collected on a NIRSYSTEM 6500 (Foss, Silver Spring, MD, USA), in duplicate in standard circular cups (diameter $3.75 \mathrm{~cm}$ ) and averaged. All calibrations were performed with $\mathrm{mPLS}$ procedures in WinISI software. Several mathematical pretreatments of spectra were tested to identify the most adequate. A validation was performed by randomly removing 25 samples before calibrating, and applying the calibrations obtained on these samples. 


\section{RESULTS AND DISCUSSION}

The chemical composition showed that the average $\mathrm{N}$ content was $5.19 \% \mathrm{DM}$ and varied widely (range 1.11$8.48 \% \mathrm{DM}, \mathrm{SD}=1.40 \%)$. N content was related to treatment and culture duration. DM55 content was 19.0\%TM on average (range 10.7\%-33.0\%) and ash content was 19.6\%DM on average (range 10.3-36.1\%DM).
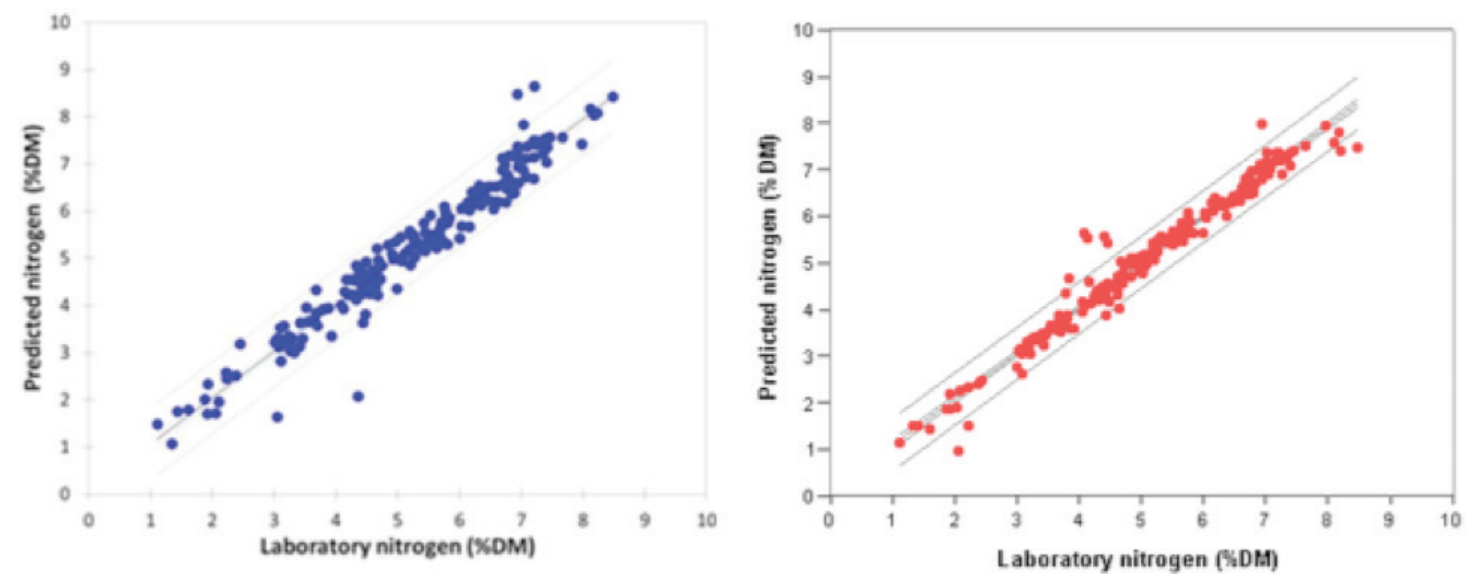

Figure 1. Calibration of total nitrogen (\%DM) on fresh Ulva (left) and dried Ulva (right)

Calibration regression between measured and predicted values of nitrogen content obtained on fresh samples is shown on Figure 1. NIRS calibrations developed on fresh samples (Table 1) led to SECV and RPDcV (=SD/ SECV) values of $1.24 \%$ and 3.3 for DM55, 2.67\%DM and 1.7 for ash and $0.40 \% \mathrm{DM}$ and 4.0 for $\mathrm{N}$ respectively. Validation showed that DM55, ash and $\mathrm{N}$ calibrations were robust since SEP values $(1.08 \%, 2.45 \% \mathrm{DM}$ and $0.49 \%$ DM respectively) were close to SECV. However, calibration for ash was less precise and less robust than for DM55 and $\mathrm{N}$ as indicated by SECV and SEP quite high compared to SEC values.

As expected, calibration for $\mathrm{N}$ on dried samples was more precise than on fresh samples, with SEP values of $0.23 \% \mathrm{DM}$ and $0.49 \% \mathrm{DM}$ in dry and fresh samples respectively. Ash was also better calibrated on dry samples but the SEP was still high (nearly 3\%DM) and RPD=3.3 (Table 1). Calibration for nitrogen on dried samples was comparable to those obtained by Bastianelli et al. (2010) on poultry excreta in the same range of nitrogen content and by Hay et al. (2010) on brown alga (Sargassum) with high $\mathrm{R}^{2}$ val of $0.99,0.95$ and 0.98 respectively.

Table 1. Calibration statistics Dry matter, Ash and Nitrogen content for fresh and dried Ulva sp. samples.

\begin{tabular}{|c|c|c|c|c|c|c|c|c|c|c|c|c|c|}
\hline \multirow[b]{2}{*}{ Spectra } & & \multirow[b]{2}{*}{$\mathbf{N}$} & \multirow[b]{2}{*}{ Mean } & \multirow[b]{2}{*}{ SD } & \multicolumn{2}{|c|}{ Calibration } & \multicolumn{3}{|c|}{ Cross-validation } & \multicolumn{4}{|c|}{ Validation } \\
\hline & & & & & SEC & $\mathbf{R}^{2}$ cal & SECV & $R^{2} c v$ & RPDcv & SEP & $R^{2}$ val & Slope & Bias \\
\hline & $\mathrm{DM}_{55}(\%)$ & 173 & 19.0 & 4.08 & 1.02 & 0.94 & 1.24 & 0.91 & 3.3 & 1.08 & 0.93 & 0.96 & 0.28 \\
\hline \multirow[t]{3}{*}{ Fresh } & Ash (\%DM) & 146 & 19.6 & 4.59 & 1.64 & 0.87 & 2.67 & 0.66 & 1.7 & 2.45 & 0.74 & 0.92 & 0.24 \\
\hline & $\mathbf{N}(\% D M)$ & 182 & 5.19 & 1.59 & 0.29 & 0.96 & 0.40 & 0.93 & 4.0 & 0.49 & 0.95 & 1.10 & 0.07 \\
\hline & DM (\%) & 205 & 89.9 & 3.87 & 0.48 & 0.98 & 0.55 & 0.98 & 7.0 & 1.16 & 0.88 & 0.86 & -0.40 \\
\hline \multirow[t]{2}{*}{ Dry } & Ash (\%DM) & 160 & 19.8 & 4.98 & 1.18 & 0.94 & 1.49 & 0.91 & 3.3 & 2.98 & 0.64 & 0.80 & -0.17 \\
\hline & $\mathbf{N}(\% D M)$ & 203 & 5.18 & 1.40 & 0.15 & 0.99 & 0.19 & 0.98 & 7.4 & 0.23 & 0.99 & 1.05 & 0.05 \\
\hline
\end{tabular}

$\mathrm{N}$ : number of samples in calibration; SD: standard deviation; SEC: standard error of calibration; $\mathrm{R}^{2}$ cal: coefficient of determination of calibration; SECV: standard error of cross validation; $\mathrm{R}^{2} \mathrm{cv}$ : coefficient of determination of cross validation; RPDcv = SD/SECV; SEP: standard error of prediction; $R^{2}$ val: coefficient of determination of validation. Bias, slope: regression between measured and predicted values. 

Direct measurement and prediction on fresh samples was applied to monitor the evolution of the protein content of Ulva in different culture conditions. The objective was to raise the nutritive value of the Ulva meal towards its inclusion in fish feed. Figure 2 shows that mean protein content (predicted nitrogen $x$ 5.0) increased from $15 \% \mathrm{DM}$ to $35 \%$ DM after 15 days with ammonia and phosphate fertilization. When carbon supplementation was applied in addition to nitrogen and phosphate, the protein content of the Ulva was lower, around 25\%DM whereas it slightly decreased in the control culture condition. The lower protein gain in the $2^{\text {nd }}$ culture condition was likely due to a higher biomass increase, which diluted protein in additional polysaccharides.

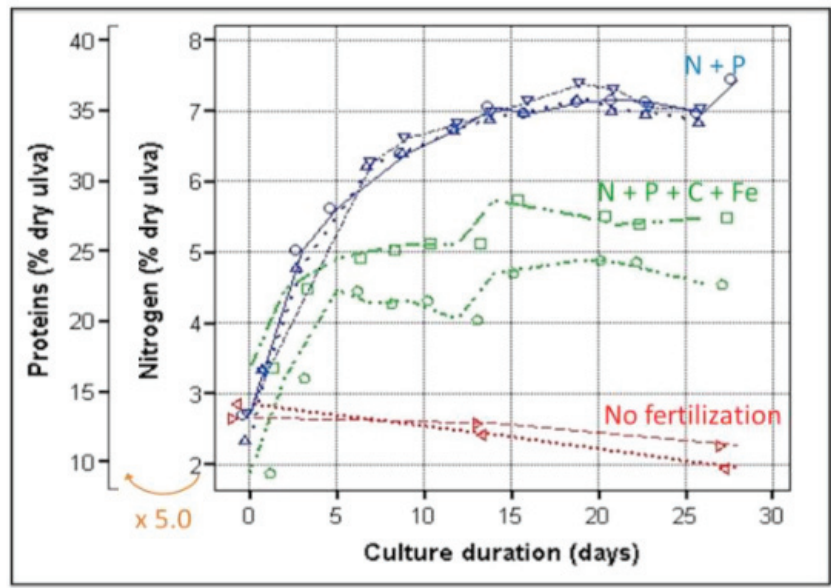

Figure 2. Kinetics of the nitrogen enrichment of Ulva. based on the predictions issued from dry samples.

\section{CONCLUSION}

The results obtained allow a routine use of NIRS on fresh samples to monitor dry matter and nitrogen content of algae during cultivation for $\mathrm{N}$ enrichment. This is a useful tool since there is no use keeping the algae in cultivation as soon as they reach a plateau of $\mathrm{N}$ concentration around 7\%DM. This level corresponds to a protein content around 35\% DM considering protein/nitrogen ratio of 5.0 instead of $5.6^{3}$ due to the possible presence of non-protein nitrogen.

\section{Acknowledgments}

Ulva cultivation was done at the IFREMER aquaculture research station in Palavas (France). Research was funded by CIRAD and IFREMER.

\section{References}

1. Bastianelli, D.; Bonnal, L.; Juin, H.; Mignon-Grasteau, S.; Carré, B.; Davrieux, F. Prediction of the chemical composition of poultry excreta by near infrared spectroscopy. J Near Infrared Spectrosc, 2010, 18, 69-77.

2. Hay, K.B.; Millers, K.A.; Poore, A.G.B.; Lovelock, C.E. The use of near infrared reflectance spectrometry for characterization of brown algal tissue. J Phycol., 2010, 46(5), 937-946.

3. Lourenço, S.O.; Barbarino, E.; De-Paula, J.C.; Lanfer Marquez, U.M.; Pereira, L.O.D.S. Amino acid composition, protein content and calculation of nitrogen-to-protein conversion factors for 19 tropical seaweeds. Phycol Res, 2002, 50(3), 233-241. 